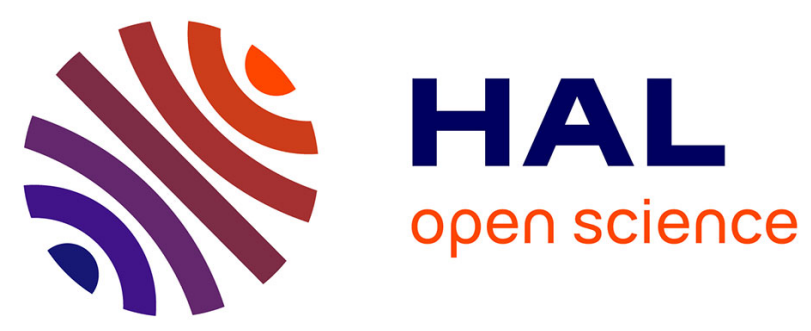

\title{
ION MOBILITY SPECTROMETRY FOR FOOD QUALITY AND SAFETY
}

Wolfgang Vautz, Dunja Zimmermann, Michelle Hartmann, Jörg Ingo

Baumbach, Jürgen Nolte, Johannes Jung

\section{- To cite this version:}

Wolfgang Vautz, Dunja Zimmermann, Michelle Hartmann, Jörg Ingo Baumbach, Jürgen Nolte, et al.. ION MOBILITY SPECTROMETRY FOR FOOD QUALITY AND SAFETY. Food Additives and Contaminants, 2006, 23 (11), pp.1064-1073. 10.1080/02652030600889590 . hal-00577501

\section{HAL Id: hal-00577501 \\ https://hal.science/hal-00577501}

Submitted on 17 Mar 2011

HAL is a multi-disciplinary open access archive for the deposit and dissemination of scientific research documents, whether they are published or not. The documents may come from teaching and research institutions in France or abroad, or from public or private research centers.
L'archive ouverte pluridisciplinaire HAL, est destinée au dépôt et à la diffusion de documents scientifiques de niveau recherche, publiés ou non, émanant des établissements d'enseignement et de recherche français ou étrangers, des laboratoires publics ou privés. 


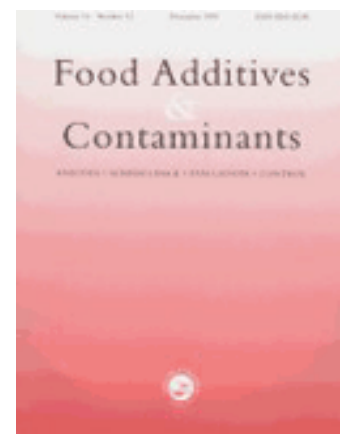

\section{ION MOBILITY SPECTROMETRY FOR FOOD QUALITY AND SAFETY}

\begin{tabular}{|r|l|}
\hline Journal: & Food Additives and Contaminants \\
\hline Manuscript ID: & TFAC-2005-367.R1 \\
\hline Manuscript Type: & Original Research Paper \\
\hline Author: & 23-Jun-2006 \\
\hline Complete List of Authors: & $\begin{array}{l}\text { Vautz, Wolfgang; ISAS, Metabolomics } \\
\text { Zimmermann, Dunja; ISAS, Metabolomics } \\
\text { Hartmann, Michelle; ISAS, Metabolomics } \\
\text { Baumbach, Jörg Ingo; ISAS, Metabolomics } \\
\text { Nolte, Jürgen; ISAS, Metabolomics } \\
\text { Jung, Johannes; DAB }\end{array}$ \\
\hline Methods/Techniques: & $\begin{array}{l}\text { food process control, food quality control, food safety control, ion } \\
\text { mobility spectrometry }\end{array}$ \\
\hline Additives/Contaminants: & contaminants, flavour, metabolites, Volatiles \\
\hline Food Types: & Beer, Beverages, Cheese, Wine \\
\hline \multicolumn{2}{|l}{} \\
\hline
\end{tabular}

\section{SCHOLARONE Manuscripts}




\title{
ION MOBILITY SPECTROMETRY FOR FOOD QUALITY AND SAFETY
}

\author{
W. Vautz ${ }^{1 *}$, D. Zimmermann ${ }^{1}$, M. Hartmann ${ }^{1}$, J.I. Baumbach ${ }^{1}$, J. Nolte ${ }^{1}$ and J. Jung ${ }^{2}$
}

${ }^{1}$ ISAS - Institute for Analytical Sciences, Dept. of Metabolomics, Bunsen-Kirchhoff-Str. 11, 44139 Dortmund, Germany

${ }^{2}$ Dortmunder Actien-Brauerei AG (DAB), Steigerstraße 20, 44145 Dortmund, Germany

"corresponding author Vautz@ansci.de

\begin{abstract}
Ion mobility spectrometry is known as a fast and sensitive technique for the detection of trace substances and is increasingly in demand not only for the protection against explosives and chemical warfare agents, but also for new applications in medical diagnosis or process control. Generally, a gas phase sample is ionised by help of UV-light, B-radiation or partial discharges. The ions move in a weak electrical field towards a detector. During their drift they collide with a drift gas flowing in the opposite direction and therefore are slowed down depending on their size, shape and charge. As a result, different ions reach the detector at different drift times which are characteristic for the ions considered. The number of ions reaching the detector is a measure of the concentration of the analyte. The method enables the identification and quantification of analytes with high sensitivity ( $\mathrm{ng} / \mathrm{L}$ range). The selectivity can even be increased - as necessary for the analyses of complex mixtures - using pre-separation techniques such as gas chromatography or multi-capillary columns. No pre-concentration of the sample is necessary. Those characteristics of the method are preserved even in air with up to $100 \%$ relative humidity. The suitability of the method for application in the field of food quality and safety - including storage, process and quality control as well as characterisation of food
\end{abstract}


stuff - was investigated in recent years for a number of representative examples which are summarized in the following including new studies as well:

- Detection of metabolites from bacteria for identification and control of their growth.

- Process control in food production - beer fermentation as an example.

- Detection of the metabolites of mold for process control during cheese production, for quality control of raw materials or for the control of storage conditions.

- Quality control of packaging materials during the production of polymeric materials.

- Characterisation of products - wine as an example.

The challenges of such applications were the operation in humid air, fast on-line analyses of complex mixtures, high sensitivity - detection limits have to be e.g. in the range of the odour limits - and in some cases the necessity of mobile instrumentation. It could be shown that ion mobility spectrometry is optimally capable of fulfilling those challenges for many applications.

Keywords: ion mobility spectrometry, quality control, process control, food production, food quality, food safety, metabolomics 


\section{INTRODUCTION}

Food quality and safety is an important issue not only for the comfort of the consumer but also related to human health [e.g. Peshin et al. 2002, Bordajandi et al. 2004] and for the benefit of the producer. The quality and origin of raw materials, the development of the production process as well as packaging and storage are relevant in this context. The growth of bacteria and mould can deteriorate the quality of raw materials and final products and may disturb the production process [e.g. Mbgua et al. 2004, Annan et al., 2003]. Furthermore, their metabolites may affect human health [e.g. Chung et al. 2005]. The origin and quality of raw materials as well as storage conditions will influence the characteristics of the final product. The development of the production process is responsible for the quality of the product on the one hand and has to be controlled properly and terminated in good time in the economic interest of the producer [Conte et al. 1999, Tarkiainen et al. 2005]. In addition, many efforts are made to characterise the final product of a food production process for it's quality and sensory characteristics [e.g. Coghe et al. 2004, Fritsch and Schieberle 2005]. Finally, suitable packing and storage is required to keep the quality of the final product [Sanders et al. 2005].

\footnotetext{
Taking samples for analysis during all stages of food production is obviously a direct way to control quality and safety. But the procedure is elaborate because the implementation of an automatic sampling system is required and samples have to prepared for the following analyses in the laboratory. On the other hand, many volatile compounds carry significant information about the characteristics of their source. Therefore, the analyses of volatiles in the headspace of a sample could be an indirect but - in the experimental point of view - much easier and faster method to control a process or the quality of foodstuff.
}

Traditionally, selective and sensitive headspace analyses during food production or of raw materials requires in general enrichment of the sample air and later analyses in the laboratory 
using spectroscopic methods [e.g. Conte et al. 1999]. Standard analytical techniques like atomic absorption spectroscopy, gas chromatography and mass spectroscopy have in common that they are time consuming and expensive as well and that they require pre-concentration of the sample [e.g. Wang et al. 2004]. Therefore, on-line or on-site measurements are rather elaborate. During recent years olfactometry as well as so-called electronic noses and tongues are increasingly in the use for quality control of or characterisation foodstuff [Bendedetti et al. 2004, Pardo and Silverbergi 2004, Hallier et al. 2004, Legin et al. 1999].

A fast and sensitive low-cost on-line and on-site detection of the relevant volatiles would be a powerful tool in the field of food quality and safety control. Ion mobility spectrometry - which was developed first for the detection of narcotics, explosives and chemical warfare agents [Eiceman and Karpas 2005, Baumbach and Eiceman 1999] - offers such characteristics. Depending on the ionisation energy necessary to ionise relevant analytes, ion mobility spectrometry enables the detection of a huge number of volatiles including e.g. alcohols, aldehydes, alkanes, cyclo-alkanes, amines, aromatic amine, aromatics, esters, ketones, pyridines, organo-phosphorus compounds, polycyclic aromatic hydrocarbons and volatile acids as concluded by Eiceman and Karpas (2005) for more than 220 detected substances. Many of them are also relevant for food quality and safety as they are e.g. known as metabolites from mold and bacteria or are related to other characteristics of their sources. Typical detection limits using ion mobility spectrometry are found in the lower $\mathrm{ng} / \mathrm{g}$ and often in the $\mathrm{ng} / \mathrm{kg}$ range and by that are in the range of odour thresholds in many cases.

At ISAS - Institute for Analytical Sciences, ion mobility spectrometry was applied successfully on various examples in the field of food quality and safety in recent years. Most recently investigations were carried out especially related to chracterisation, food safety and process control. After an introduction in ion mobility spectrometry a number of representative studies will be presented in detail, including process control of beer fermentation and cheese production as 
well as quality control with regard to contamination by mold or bacteria. Finally the possibility of characterisation of foodstuff and the control of the quality of packaging materials will be discussed.

\section{MATERIALS AND METHODS}

\section{Ion Mobility Spectrometry}

In an ion mobility spectrometer (IMS) the sample air is ionised using B-radiation, UV light or partial discharges. Radioactive sources as well as partial discharges ionise the present gas and the resulting so-called reactant ions transfer charges to the analyte molecules. The reactant ions cause the "reactant ion peak" (RIP) in the IMS spectra. Using UV-light the analyte molecules are ionised directly - no reactant ions are formed [Eiceman and Karpas 2005].

In a second step, the ions will move in a weak electric field towards a Faraday plate used as detector. A shutter grid initially avoids the drift of ions in the field and only when it is opened for short time intervals $(30-1,000 \mu \mathrm{s})$, an ion swarm enters the so-called drift region of an IMS and moves towards the detector plate. In the opposite direction a drift gas flow is applied which avoids neutral analyte molecules from entering the drift region. Furthermore, the ions collide with the drift gas molecules, thus being slowed down depending on their size, shape and charge. Finally, a rather constant drift velocity of the ions will be realised due to energy gain from the electric field and loss by various collisions with other gas molecules.

The time the ions need to cover the drift distance from the shutter grid to the detector - the socalled drift time - is characteristic for the analyte ion. The number of detected ions is a measure for the concentration of the analyte. From the drift time and the instrumental parameters the 
reduced ion mobility $\mathrm{K}_{0}$ can be calculated, considering the influence of ambient pressure and temperature as:

$$
K_{0}=\frac{\ell}{E \times t} \times \frac{p}{p_{0}} \times \frac{T_{0}}{T}
$$

with: $\quad \ell-$ length of the drift region in $\mathrm{cm}$

$E$ - electric field strength in $\mathrm{V} / \mathrm{cm}$

$t$ - drift time in s,

$p$ - atmospheric pressure in hPa $\left(p_{o}=1,013.2 \mathrm{hPa}\right)$

$T$ - temperature of the drift gas in $\mathrm{K}\left(T_{o}=273.2 \mathrm{~K}\right)$

The acquisition of a complete ion mobility spectrum needs less the $100 \mathrm{~ms}$. The use of ambient air as drift and carrier gas avoids the use of expensive and unhandy gases of high purity. The instruments are operated under ambient temperature and pressure and furthermore can be miniaturised. Therefore, ion mobility spectrometry is optimally capable for fast on-line and onsite detection of volatiles also in humid air under ambient conditions without expansive sampling, enrichment and later analyses in the laboratory as it is the case using traditional methods [e.g. Hallier et al. 2004].

\section{Pre-Separation}

If complex mixtures are under investigation, several analytes which are present may have similar drift times. To enable their identification anyhow, pre-separation can be used to obtain additional information for identification from the retention times of the analytes in a gaschromatographic (GC) or multi-capillary column (MCC) [Xie et al. 2002, Baumbach et al. 2003]. Furthermore this avoids negative effects from clustering in the ionisation chamber when humid air is analysed: Using pre-separation the water molecules and the analyte molecules enter the ionisation chamber successive. Therefore relevant substances can be detected even in humid 
air up to $100 \%$ relative humidity without negative effects on the detection limits [Vautz et al. 2004a]. Using pre-separation techniques, the analyte is introduced discontinuously by a 6-way valve into the column (variable time steps depending on the retention time of the analyte in the column, introducing $1 \mathrm{~mL}$ volume each time).

\section{Calibration}

For calibration of the IMS, permeation cells [Vautz et al. 2004b] were filled with standard analyte (puriss. p.a., Sigma-Aldrich) using a $1 \mathrm{~mL}$ tube closed with a membrane. This permeation cell was placed into a $150 \mathrm{~mL}$ bottle and exposed to a carrier gas flow of $100 \mathrm{~mL} / \mathrm{min}$. The concentration of the resulting calibration gas could be determined from the flow rate and from the weight of the permeation cell before and after the experiment. For the analytes investigated here, the initial concentrations for the exponential dilution were in the range of 1-100 mg/L. A 1 $\mathrm{L}$ bottle was flown through by the calibration gas for 2 hours to guarantee complete exchange of the air to the sample. Then this bottle was rinsed with a constant flow of synthetic air, thus leading to an exponential dilution of the initial concentration. The calibration curves can be used for the quantification of a detected signal. Detection limits were obtained from a signal/noise ratio of $1: 3$ and were found in the range of $\mu \mathrm{g} / \mathrm{L}$ down to $\mathrm{ng} / \mathrm{L}$ depending on the analyte and on the ionisation method.

\section{Experimental}

For the presented investigations ion mobility spectrometers with UV light (UV-IMS) as ionisation source were used as well as B-radiation $\left({ }^{63} \mathrm{Ni}-\mathrm{IMS}\right)$. For pre-separation gas-chromatographic (GC) and multi-capillary columns (MCC) were used in the combination GC-UV-IMS and MCC${ }^{63} \mathrm{Ni}-\mathrm{IMS}$. The instruments were operated at ambient pressure. They were built at ISAS and have been applied successfully for the detection of various trace gases in the range of $n g / L$ to 
$\mathrm{pg} / \mathrm{L}$ (ppbv-pptv range). Applications were e.g. the analyses of human breath or the detection of the metabolites of mold [Ruzsanyi et al. 2003]. Further details of the IMS and its application have been described elsewhere [Xie et al. 2002, Sielemann et al. 1999]. In all cases, dry synthetic air was used as drift and carrier gas. The determined drift time as well as the calculated ion mobility were corrected for temperature and pressure [Vautz et al. 2004a, Vautz et al. 2004b]. For details of the experimental setup, see Figure 1 and Table 1.

\section{PROCESS CONTROL}

\section{Beer Fermentation}

The fermentation process of beer is a time-consuming part of the complete beer production process and takes 5 to 6 days. The end of the process is determined by concentration thresholds for diacetyl and 2,3-pentandione [Hough 1985] because of their smell like rancid butter. Both substances are formed in the beginning of the fermentation process and later are degraded while the process is going on. Their concentrations have to be decreased consequently below the human odour threshold. Furthermore the ratio of both substances is a measure for potential micro-biotic contamination which can occur during the fermentation process.

In a brewery, the concentrations are determined by taking and preparing samples manually before a gas-chromatographic headspace analysis in the laboratory. The full procedure takes about 3 hours. Therefore, this kind of analysis is made only once a day and no continuous concentration data are available. On-line methods are not available at present. In small breweries where no laboratory is available, the fermentation is extended with up to 5 days to assure sufficient degradation of both analytes without analyses. 
Using a GC-UV-IMS the detection of both relevant analytes in the matrix of different beer types was possible within less than 10 min [Vautz 2004d]. The variation of the total ion current with the retention time of the GC-columns is shown in Figure 2, left. After a baseline correction the quantification of both concentrations was possible by calculation of the peak area. A comparison with the results of the breweries routine analyses of beer samples after different fermentation time showed good agreement (see Figure 2, right). Both analytes can be detected and quantified below the odour threshold - even in beer ready for consumption in some cases traces of diacetyle and 2,3.-pentandione could be detected. Therefore using GC-UV-IMS a continuous on-line control of the concentration of the analytes responsible for the termination of the process is possible.

\section{Cheese Production}

For this study, the headspace of a complete camembert cheese and of parts of the cheese without the rind was introduced into the GC-UV-IMS. The detection of the metabolites of the camembert cheese with a GC-UV-IMS and of the cheese after complete removal of the rind showed that the metabolites from the camembert fungi can be differentiated from the volatiles of the cheese itself. The signal height enables quantification, especially of those peaks identified as metabolites from the mould fungi. Therefore, the method developed can be used for control of the growth of mould.

\section{QUALITY CONTROL}

\section{Detection of the Metabolites from Mould}

The detection of metabolites from mould as shown above enables not only the control of the growth of wanted mould but also of unwanted moulds as it could appear e.g. during storage of raw materials or even final products. In this case, not only one mould type will contribute to the 
culture but various types as they are available in ambient air. Therefore, the IMS spectra and chromatograms are expected to be more complex - various analytes can be expected as metabolites [Ruszanyi et al. 2003].

Figure 3 shows the variation of the IMS chromatogram of a bread mould culture which was investigated over a period of one month weekly. Without a detailed discussion of the contributing mould types, it is obvious that the shape of the chromatogram changes significantly during this period. Especially the signal at about $530 \mathrm{~s}$ retention time is growing strongly during the first 3 weeks. This indicates that not only the detection and identification of mould but also information about the state of the mould culture can be obtained using GC-UV-IMS.

As ${ }^{63} \mathrm{Ni}-\mathrm{IMS}$ are in general more sensitive, identification of different mould types from the complete 3-dimensional IMS spectra (drift time, retention time and signal height) should be possible. Such investigations are planned for the near future. The growth of a mould culture then can be described from the changes a 3-dimensional plot (drift time, retention time and peak height) as shown e.g. in Figure 5. Quantification is possible using the peak volume. Identification will be possible when using peak pattern as for the identification of bacteria as shown in the next section.

\section{Detection of Metabolites from Bacteria}

In the frame of investigations of human breath [Ruszanyi et al. 2005a, Ruszanyi et al. 2005b], the metabolites of various bacteria were investigated in detail not only in breath but also growing on controlled bacteria cultures. The metabolites of those bacteria were detected using a MCC $-{ }^{63} \mathrm{Ni}-\mathrm{IMS}$. With statistical methods specific pattern of signals (retention time/drift time) could be determined for 10 different bacteria and a fungi which are relevant for pulmonary 


\begin{abstract}
diseases (see Figure 4). Those pattern were used successfully to detect the bacteria in the breath of patients directly.
\end{abstract}

For sure related to food quality and safety different bacteria should be taken into account. But the procedure of definition of typical peak pattern for each bacteria or mold type and later identification e.g. in the headspace of a sample or in the ambient air in a storage location will be similar.

\title{
CHARACTERISATION
}

Many volatiles emitted from foodstuff are relevant for the character of the source as they are related to flavour, taste or quality [e.g. Wang et al. 2004]. Similar to the use of the metabolites of mould or bacteria for their identification, the volatiles emitted from any sample could also be used to characterise the sample. Figure 5, left shows the GC-UV-IMS chromatogram of a Brazilian sugar cane liquor, a French red wine and a German white wine. In this case no efforts were made to quantify the signals. But however it is obvious that the liquor causes a higher ethanol signal at about 1 min retention time than the other beverages while the further slope is relatively flat. Both wines show more clear signals and moreover there are significant differences between both wines. This demonstrates that not only liquor from wine but also red and white wine could be differentiated. Further investigations with various other wines showed that even between different red wines or between different white wines significant different signals can be observed. The full 3-dimensional IMS spectra - as shown in Figure 5 right for a German white wine - can be used to define characteristic peak pattern for different types of wine for differentiation from other types and for quality control as well.

\section{PACKAGING MATERIALS}

Finally, any foodstuff has to be packed before vending. Polymeric materials as commonly used for packaging of foodstuff are the product of polymerisation of up to 3 monomers. Those 
monomers play an important role as allergens and may be responsible for various lung diseases. Therefore an accurate control of the monomere concentration in the final polymer is strongly recommended in the interest of the consumer as well as in the interest of the producer. Using a ${ }^{63} \mathrm{Ni}-\mathrm{IMS}$ without pre-separation, the remaining traces of monomers in the polymer after complete polymerisation could be detected as shown in Figure 6. As already mentioned before, those traces can be quantified by help of a calibration carried out earlier. Therefore IMS can be used to control the compliance of threshold concentrations of monomers in packaging materials.

It is obvious, that such a sensitive method can also be used for control of the polymerisation process itself as shown in Vautz et al. 2004d. The concentration of monomers in the mixture during the polymerisation process was measured using a UV-IMS without pre-separation which analysed the headspace over a continuous droplet flow from the reaction tank. The process can be described with sufficient sensitivity and with a fast response of the headspace concentration on the concentration in the mixture.

However, the monomer concentration in the final polymer does not directly reflect the migration of the monomere into the packaged foodstuff. But it provides information about the potential for contamination of the foodstuff and after investigations of the uptake mechanisms of particular foodstuffs, the possible contamination can be estimated.

\section{CONCLUSION}

The investigations described above demonstrate the qualification of ion mobility spectrometry as a powerful tool for food process, quality and safety control. For each particular problem first of all the relevant volatiles have to be defined as they are correlated to the characteristics of the investigated foodstuff to be described. Then the suitable ionisation source and optionally a reasonable pre-separation have to be chosen. Finally the ion mobility spectrometer can be used 
- even when necessary in a miniaturised version - for fast, sensitive and selective on-line control of food quality, process development, packaging materials or storage conditions.

\section{ACKNOWLEDGEMENTS}

Financial support has been given by the German Federal Ministry of Education, Science, Research and Technology and the Ministry of Science and Research of the State of NorthrhineWestfalia. The dedicated and accurate work of Luzia Seifert and Stefanie Güssgen during the experiments was a precedent condition for the successful performance of the presented investigations. The polymeric materials were generously provided by Sebastian Engell, Department of Biological and Chemical Engineering at the University of Dortmund, Germany.

\section{REFERENCES}

Annan, N.T., Poll, L., Sefa-Dedeh, S., Plahar, W.A. and Jakobsen, M., 2003. Volatile compounds produced by Lactobacillus fermentum, Saccharomyces cerevisiae and Candida krusei in single starter culture fermentations of Ghanaian maize dough. Journal of Applied Microbiology 94, 462-474.

Baumbach, J.I., Sielemann, S., Xie, Z. and Schmidt, H., 2003. Detection of the gasoline components MTBE, Benzene, Toluene and m-xylene using ion mobility spectrometers with radioactive and UV-ionization source. Analytical Chemistry 75, 1483-1490.

Baumbach, J.I., and Eiceman, G.A., 1999. Ion mobility spectrometry: Arriving on-site and moving beyond a low profile. Applied Spectroscopy 53/9, 338A-355A.

Benedetti, S., Pompei, C. and Mannino, S., 2004. Comparison of an electronic nose with the sensory evaluation of food products by "triangle test". Electroanalysis 16(21), 1801-1805.

Bordajandi, L.R., Gomez, G., Abad, E., Rivera, J., Fernandez-Baston, M.D., Blasco, J. and Gonzalez, M.J., 2004. Survey of persistent organochlorine contaminants (PCBs, $\mathrm{PCDD} / \mathrm{Fs}$, and PAHs), heavy metals ( $\mathrm{Cu}, \mathrm{Cd}, \mathrm{Zn}, \mathrm{Pb}$, and $\mathrm{Hg}$ ), and arsenic in food 
samples from Huelva (Spain): Levels and health implications. Journal of Agricultural and Food Chemistry 52 (4), 992-1001.

Chung, Y.J., Coates, N.H., Viana, M.E., Copeland, L., Vesper, S.J., Selgrade, M.K and Ward, M.D.W., 2005. Dose-dependent allergic responses to an extract of Penicillium chrysogenum in BALB/c mice. Toxicology 209/1, 77-89.

Coghe, S., Martens, E., D’Hollander, H., Dirinck, P.J. and Delvaux, F.R., 2004. Sensory and Instrumental Flavour Analysis of Wort Grewed with Dark Specialty Malts. J. Inst. Brew., 110/2, 94-103.

Conte, L. S., Moret, S., Bortolomeazzi, R. and Pizzale, L., 1999. The advancement of the assessment of food quality control as stressed by recent developments in analytical chemistry. Annali di Chimica, 89 (9-10), 805-816.

Eiceman, G.A. and Karpas, Z., 2005. Ion mobility spectrometry. CRC Press, Boca Raton, Ann Arbor, London, Tokyo.

Fritsch, H.T. and Schieberle, P., 2005. Identification based on quantitative measurements and aroma recombination of the character impact odorants in a Bavarian Pilsner-type beer. Journal of Agricultural and Food Chemistry 53 (19), 7544-7551.

Hallier, A., Courcoux, P., Serot, T. and Prost, C., 2004. New gas chromatography-olfactometric investigative method, and its application to cooked Silurus glanis (European catfish) odor characterization. Journal of Chromatography A 1056 (1-2), 201-208.

Hough, J. S., 1985. The Biotechnology of Malting and Brewing. Cambridge University Press, Cambridge, UK.

Legin, A., Rudnitskaya, A., Vlasov, Y., Di Natale, C., Mazzone, E. and D'Amico, A., 1999. Application of electronic tongue for quantitative analysis of mineral water and wine. Electroanalysis $11(10-11), 814-820$. 
Mbugua, S.K. and Gathumbi, J.K., 2004. The Contamination of Kenyan Lager Beers with Fusarium Mycotoxins. J. Inst. Brew., 110/3, 227-229.

Pardo, M. and Sberveglieri, G., 2004. Electronic olfactory systems based on metal oxide semiconductor sensor arrays, MRS Bulletin 29(10), 703-708.

Peshin, S.S., Lall, S.B. and Gupta, S.K., 2002. Potential food contaminants and associated health risks. Acta Pharmacologica Sinica 23 (3), 193-202.

Ruzsanyi, V., Baumbach, J.I., Sielemann, S., Litterst, P., Westhoff, M. and Freitag, L., 2005a. Detection of human metabolites using multi-capillary columns coupled to ion mobility spectrometers. J. Chromatographia A 1084 (1-2), 145-151.

Ruzsanyi, V., Sielemann, S. and Baumbach, J.I., 2005b. Analysis of human breath using IMS. Int. J. for lon Mobility Spectrometry 8 (1), 5-7.

Ruzsanyi, V., Baumbach, J.I. and Eiceman, G.A., 2003. Detection of the mold markers using ion mobility spectrometry, INT. J. FOR ION MOBILITY SPECTROMETRY 6 (2), 53-57.

Sanders R.A., Zyzak D.V., Morsch T.R., Zimmerman S.P., Searles P.M., Strothers M.A., Eberhart B.L. and Woo A.K., 2005. Identification of 8-nonenal as an important contributor to "plastic" off-odor in polyethylene packaging. Journal of Agricultural and Food Chemistry $53(5), 1713-1716$.

Sielemann, J.I. Baumbach, P. Pilzecker and G. Walendzik, 1999. Detection of trans-1,2dichloroethene, trichloroethene and tetrachloroethene using multi-capillary columns coupled to ion mobility spectrometers with UV-Ionisation sources. INT. J. FOR ION MOBILITY SPECTROMETRY 2, 15-21.

Tarkiainen, V., Kotiaho, T., Mattila, I., Virkajärvi, I., Aristidou, A. and Ketola, R.A., 2005. On-line monitoring of continuous beer fermentation process using automatic membrane inlet mass spectrometric system. Talanta, 65, 1254-1263. 

Vautz, W., Ruszany, V., Sielemann, S. and Baumbach, J.I., 2004a. Sensitive ion mobility spectrometry of humid ambient air using $10.6 \mathrm{eV}$ UV-IMS, INT. J. FOR ION MOBILITY SPECTROMETRY 7, 3-8.

Vautz, W., Sielemann, S. and Baumbach, J.I., 2004b. Determination of terpenes in humid ambient air using ultraviolet ion mobility spectrometry, Anal. Chim. Acta 513, 393-399.

Vautz, W., Baumbach, J.I. and Gesthuisen, R., 2004c. On-line control of polymerisation processes using ion mobility spectrometry, Int. J. Ion Mobility Spectrometry 7 (2), 7-10.

Vautz, W., Baumbach, J.I., Jung, J., 2004d. Continuous monitoring of the fermentation of beer by ion mobility spectrometry, Int. J. Ion Mobility Spectrometry 7 (2), 3-5.

Wang, L., XU, Y., Zhao, G. and Li, J., 2004. Rapid Analysis of Flavour Volatiles in Apple Wine Using Headspace Solid-Phase Microextraction. J. Inst. Brew., 110/1, 57-65.

Xie, Z., Sielemann, S., Schmidt, H., Li, F. and Baumbach, J.I., 2002. Determination of Acetone, 2-Butanone and Diethylketone Using HSCC-UV-IMS, Anal. Bioanal. Chem. 372, 606-610. 


\begin{tabular}{|c|c|c|}
\hline Ionisation sources & UV light (10.6 eV) & $\mathrm{B}$ - radiation $\left({ }^{63} \mathrm{Ni}\right)$ \\
\hline Drift length & \multicolumn{2}{|c|}{$12 \mathrm{~cm}$} \\
\hline Electric field strength & \multicolumn{2}{|c|}{$320 \mathrm{~V} / \mathrm{cm}$} \\
\hline Shutter grid opening time & $300 \mu \mathrm{s}$ & $1000 \mu s$ \\
\hline Shutter pulse & \multicolumn{2}{|c|}{$50 \mathrm{~V}$, square } \\
\hline Shutter pulse interval & \multicolumn{2}{|c|}{$20-100 \mathrm{~ms}$} \\
\hline Drift gas & \multicolumn{2}{|c|}{$100 \mathrm{~mL} / \mathrm{min}$ synthetic air } \\
\hline Carrier gas & \multicolumn{2}{|c|}{$300 \mathrm{~mL} / \mathrm{min}$ synthetic air } \\
\hline Pressure, Temperature & \multicolumn{2}{|c|}{ ambient } \\
\hline $\begin{array}{l}\text { Pre-separation } \\
\text { (optional) }\end{array}$ & $\begin{array}{l}\text { GC } \\
\text { capillary column } \\
\text { polar } \\
30 \mathrm{~m}, 30^{\circ} \mathrm{C} \text { constant }\end{array}$ & $\begin{array}{l}\text { MCC } \\
\text { multi-capillary column } \\
\text { un-polar } \\
20 \mathrm{~cm}, 30{ }^{\circ} \mathrm{C} \text { constant }\end{array}$ \\
\hline
\end{tabular}

Table 1. Experimental parameters of the applied ion mobility spectrometers. 


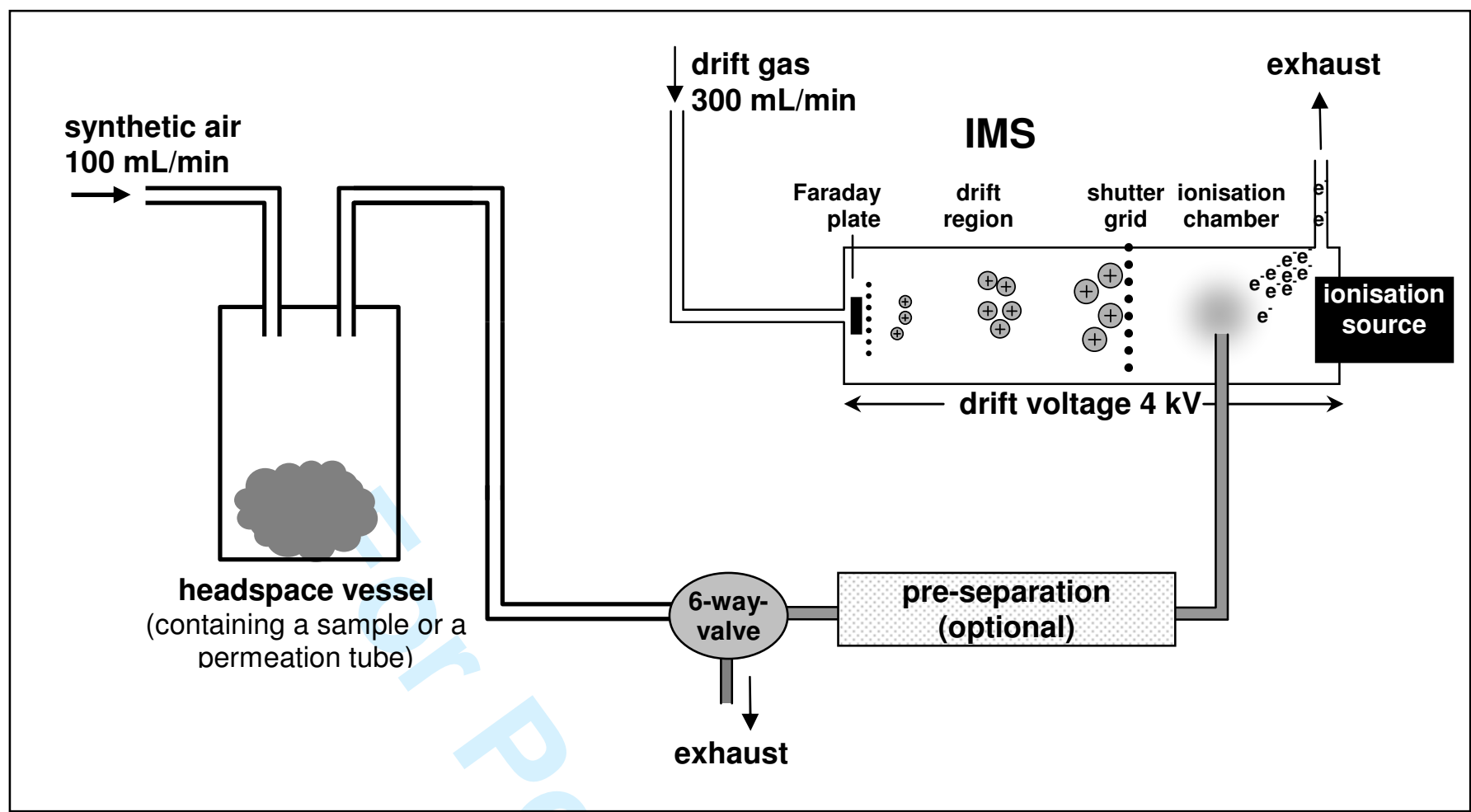

Figure 1. Scheme of an ion mobility spectrometer including pre-separation and headspace sampling unit. 


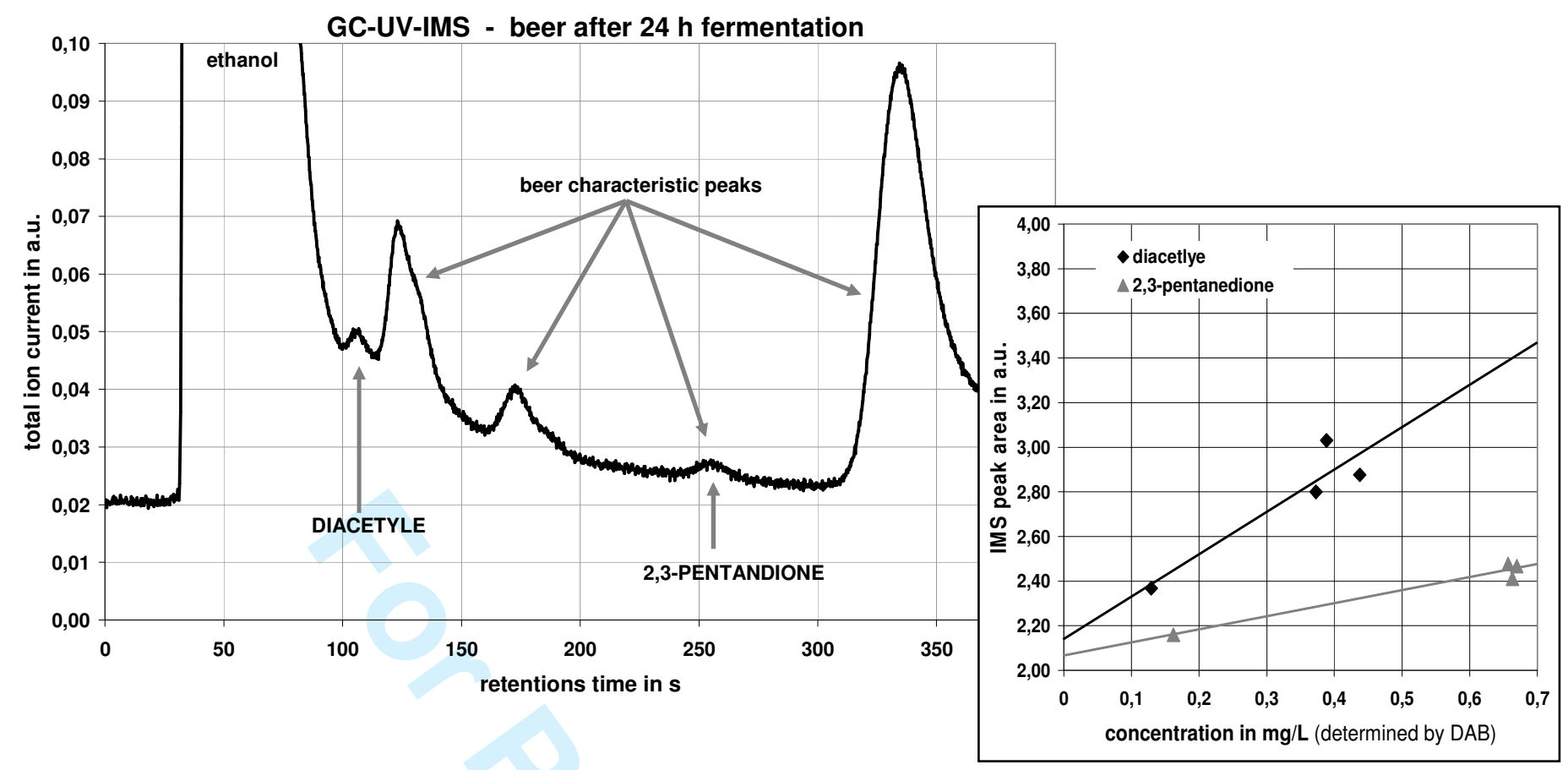

Figure 2. GC-UV-IMS chromatogram of beer (left) - the relevant diacetyle and 2,3penrtandione signals are indicated. Comparison (right) of the IMS signal peak area and the breweries routine measurements of diacetyle and pentandione for different fermentation duration. 

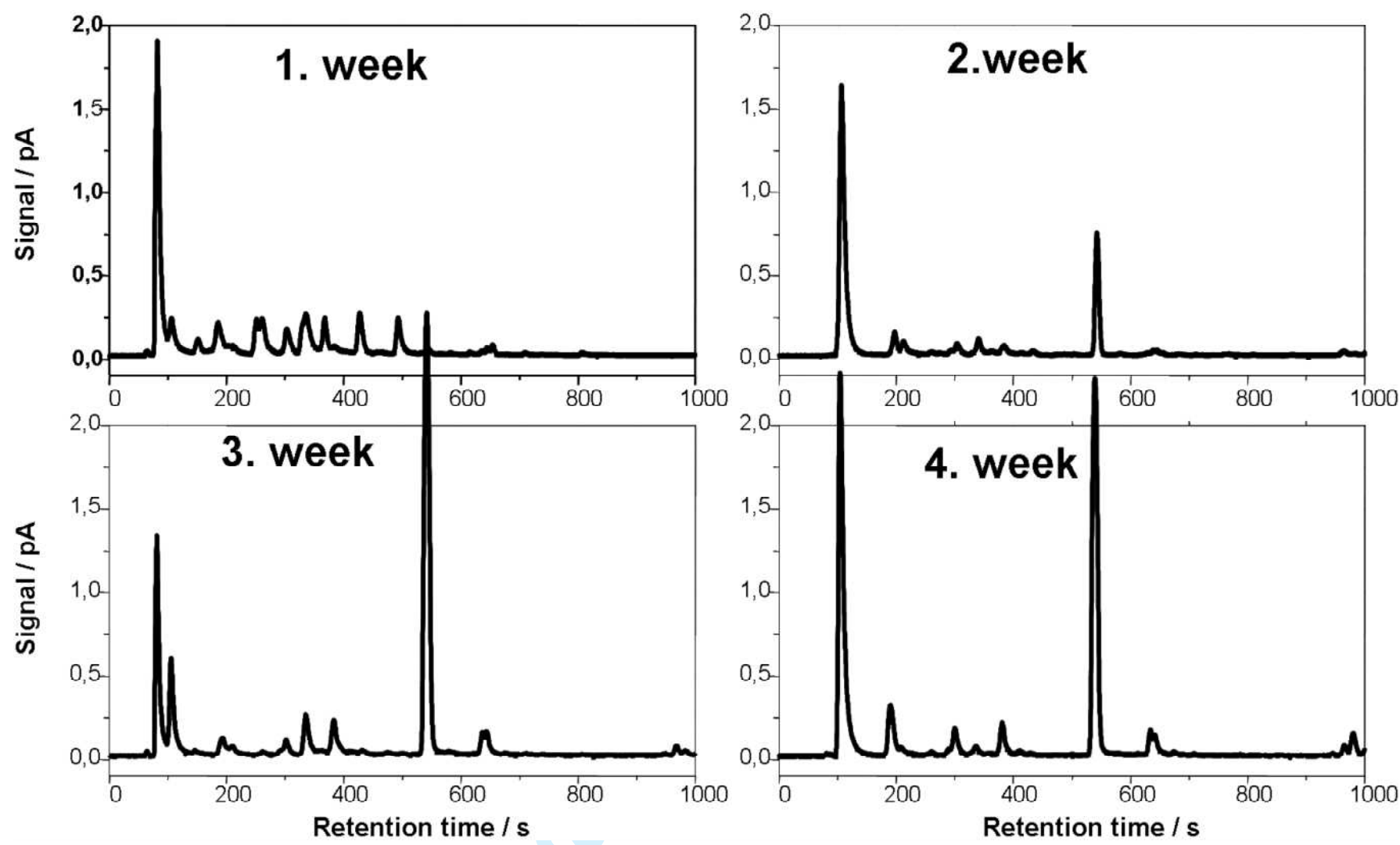

Figure 3. The growth of a mold culture leads to changes of the composition of the meatabolites. The resulting IMS chromatogram (GC-UV-IMS) can be used to characterise the state of the culture. 


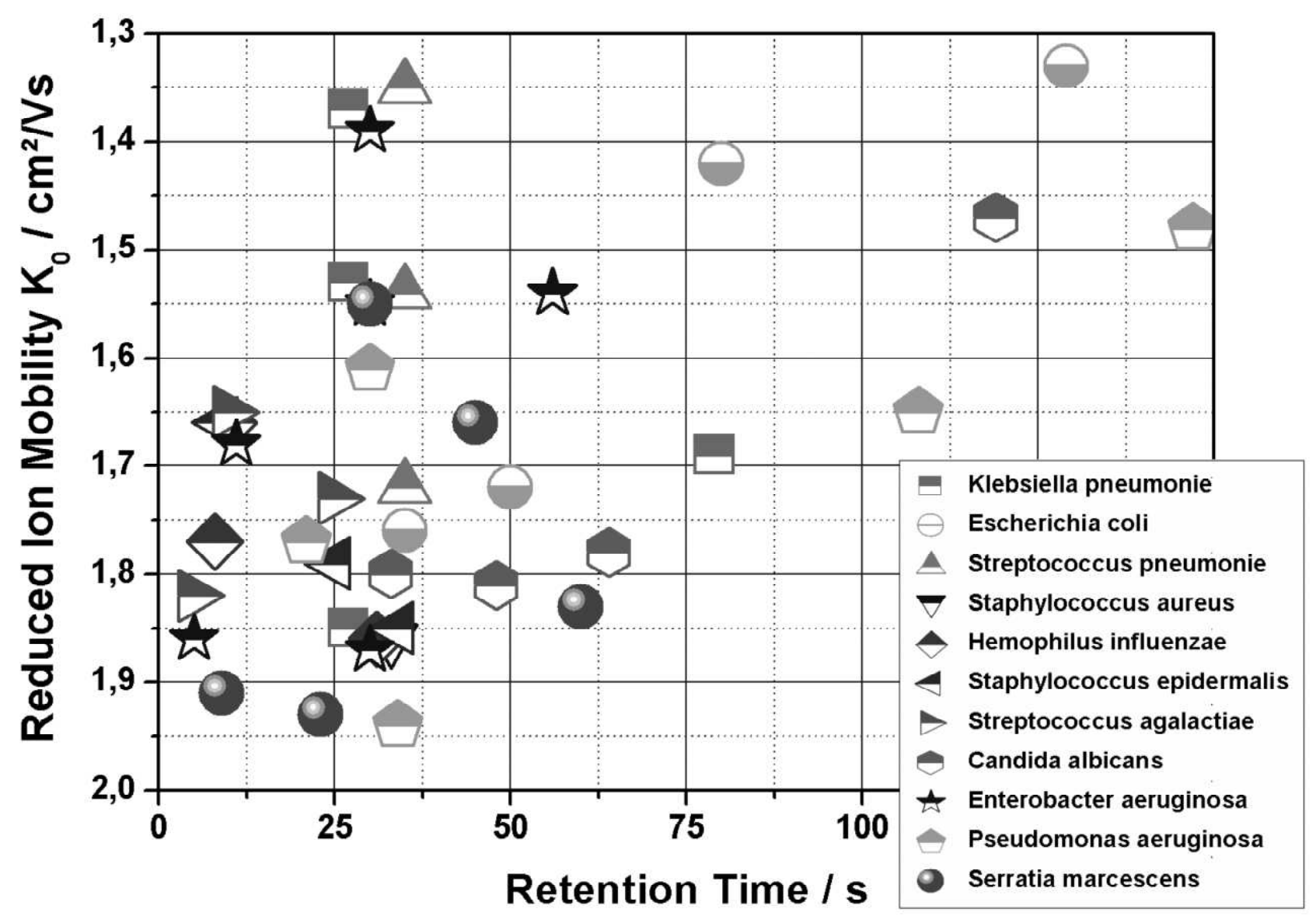

Figure 4. Identification of 9 bacteria and a fungi using their specific peak pattern. 


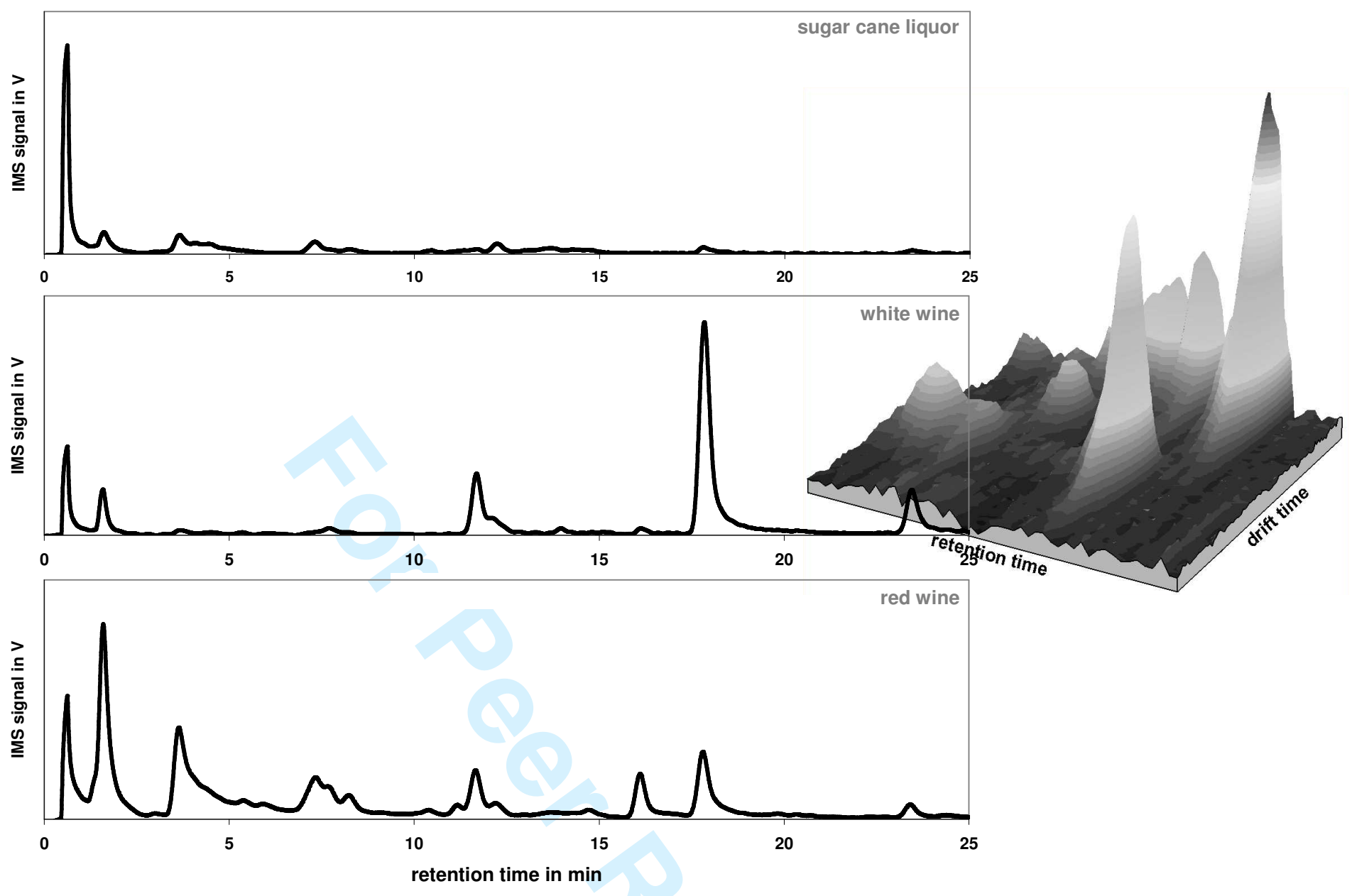

Figure 5. GC-UV-IMS chromatogram of a Brazilian sugar cane liquor (top), a German white wine (middle) and a French red wine (bottom). In addition, the full 3-dimensional IMS spectrum of the white wine is presented (right). 


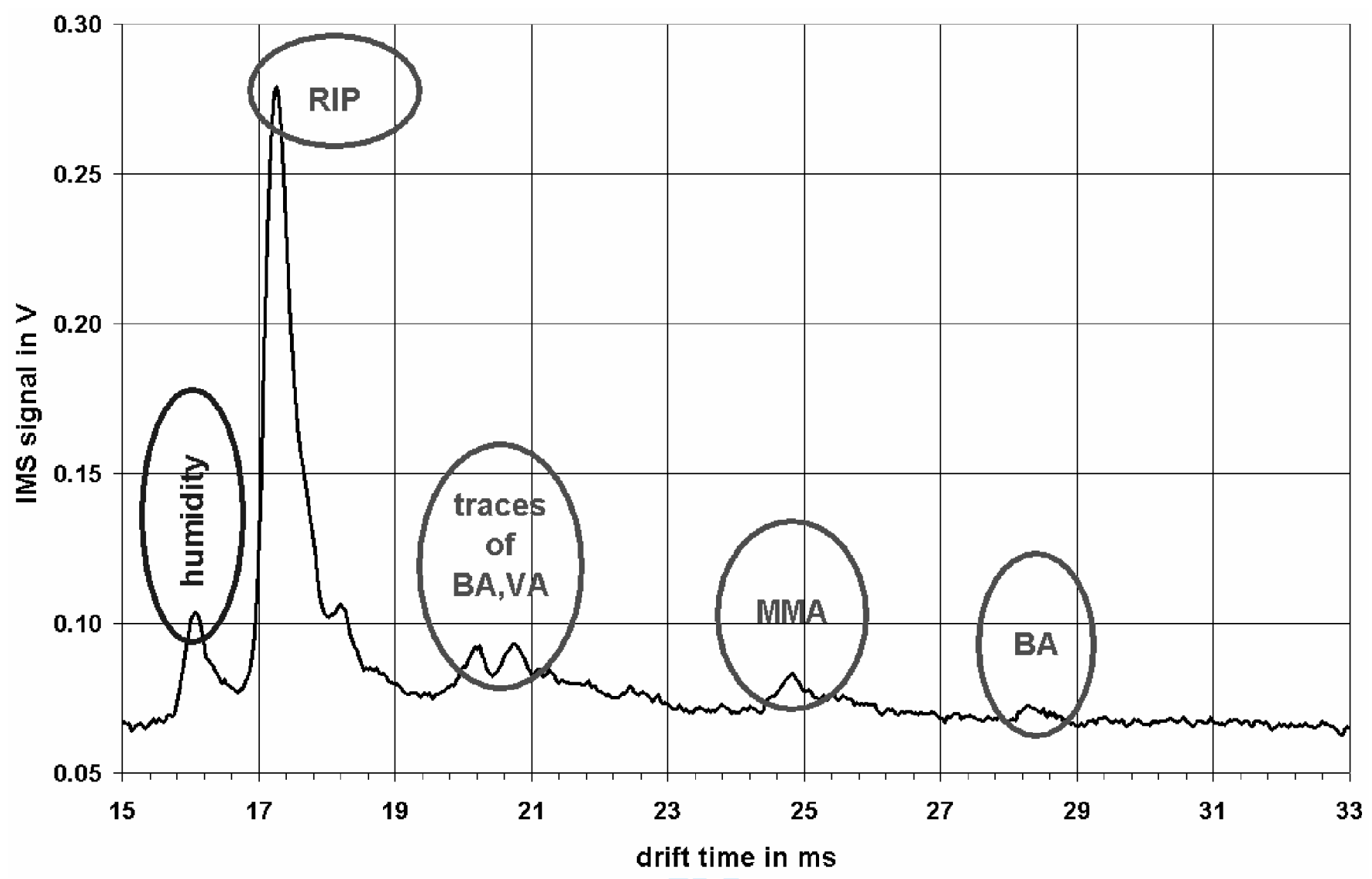

Figure 6. Traces of the initial monomers can be detected in the final polymer even after complete polymerisation. 